\title{
Using Social Media to Enable Staff Knowledge Sharing in Higher Education Institutions
}

Niall Corcoran

Limerick Institute of Technology (LIT)

niall.corcoran@lit.ie

Aidan Duane

Waterford Institute of Technology (WIT)

\section{Abstract}

Higher education institutions (HEIs) are knowledge intensive environments by nature. However, the management of organisational knowledge and the promotion of staff knowledge sharing is largely neglected in these institutions. This study examines how enterprise social networks can enable staff knowledge sharing in communities of practice in that context. The study is framed as an Action Research project, covering three cycles over a 12 month period. A conceptual model was developed for empirical testing and data was collected through focus groups and interviews, supplemented by reflective journaling and content analysis. The findings support the conceptual model and provide insight into the antecedents necessary for the creation of an enterprise social network enabled knowledge sharing environment, the motivators for and barriers to participation, and the perceived organisational and individual benefits of increased staff knowledge sharing activity. The findings indicate that the barriers to participation are influenced by the prevalent organisation structure and culture, and a divide between faculty and other staff. However, individual benefits that accrue from participation may influence greater participation, and organisational benefits that accrue may influence organisational strategies that drive change in structure and culture to promote the development of the knowledge sharing environment. A number of findings have practical implications for the management of higher education institutions, such as the evidence of a divide between faculty and other staff, and the perceived existence of an organisational culture that inhibits staff communication, interaction and collaboration. In general, the study findings provide an opportunity for educationalists to better understand the scope and impact of employing social media platforms for knowledge sharing. This study adds to the growing body of work on organisational implementations of social media, and should be of interest to practitioners and researchers undertaking similar projects.

\section{Introduction}

The importance of knowledge as a strategic asset to any organisation is increasingly recognised in tandem with a growing awareness that economies and societies have become more information and knowledge intensive (Hislop, 2013). This view of the importance of knowledge to contemporary economies and societies is typified by Stewart (1997, p. 9), who wrote that knowledge has become the "primary ingredient of what we make, do, buy and sell. As a result, managing it - finding and growing intellectual capital, storing it, selling it, sharing it - has become the most important economic task of individuals, business and nations." Goffee and Jones (2015) assert that the need for organisations to develop their human capital, or knowledge assets, has long been recognised by knowledge intensive businesses, and that there is a long-term correlation between organisational performance and investment in human 
capital. Intellectual capital is the sum of everything that everybody in an organisation knows that gives it a competitive advantage, and, according to Rao (2010), the intellectual capital of an organisation can only be maximised through the application of knowledge management (KM) practices. The importance of knowledge sharing to organisational success is also highlighted by Liebowitz (2001), who argues that organisations can attain competitive advantages through encouraging and promoting knowledge sharing. Edvinsson (2002) maintains that the nature of competitive advantage is changing and is no longer based on market position, size and power, but on the incorporation of knowledge into all of an organisation's activities.

In general, although public higher education institutions (HEIs) would not be considered in the same light as profit-driven organisations, neither are they isolated from such contemporary views of the role of knowledge in society. HEIs are, by their very nature, knowledge intensive environments and their primary raison d'être is to create and disseminate knowledge through teaching, learning and research activities. For a number of economic and social reasons, and driven by national policy, public HEIs are increasingly being operated and managed as businesses, with growing requirements to drive down costs, improve efficiencies and generate their own income (Rowley, 2000; Wohlmuther, 2008). HEIs are required to compete against each other for students in an increasingly competitive, global marketplace, and in order to be successful they need to maximise their competitive advantage (Bloom, 2005; Cranfield \& Taylor, 2008). According to Swart and Kinnie (2003), the need for knowledge sharing is even more important in knowledge-intensive organisations such as public HEIs, and they must share knowledge held by staff if they are to gain the most from their intellectual capital and compete effectively in the ever expanding, global marketplace. Therefore, it would seem logical that KM would be a core business strategy of any HEI through which they could recognise, manage and use their knowledge assets. For example, Kidwell, Vander Linde, and Johnson (2000) believe that HEIs can derive tremendous value from developing initiatives to share knowledge for the achievement of business objectives, arguing that, if done effectively, $\mathrm{KM}$ can lead to better decision making capabilities, reduced development cycle time for curriculum and research, improved academic and administrative services and reduced costs. However, studies have shown that, although the external transfer of knowledge is effectively managed by most HEIs (Kok, 2007; Pinto, 2012), the management of organisational knowledge and the promotion of staff knowledge sharing is largely neglected, with low levels of KM implementation and knowledge sharing evident in these organisations (Fullwood, Rowley, \& Delbridge, 2013; Ramachandran, Chong, \& Ismail, 2009). A number of reasons for the lack of KM implementation, and knowledge sharing in general, in HEIs can be garnered from the literature, among them: organisational structures (Collinson \& Cook, 2003; J. J. Lee, 2007; Rowley, 2000); organisational culture (Cronin, 2001; J. J. Lee, 2007; Rowley, 2000); the bureaucratic character of some types of HEIs (Taylor, 2006; Tippins, 2003), and a divide and mistrust between academic staff and administration staff (Castleman \& Allen, 1995; Conway, 2000; Dobson, 2011; Szekeres, 2004). This lack of KM implementation and knowledge sharing has significant negative impacts on the intellectual capital and consequently the operational performance of HEIs, similar to any type of organisation, commercial or otherwise. According to Ramakrishnan and Yasin (2012), speed of curriculum revision and updating, and quality of administrative and support services are particularly impacted. 


\subsection{Enterprise Social Networks as a Knowledge Management Tool}

The importance of social media as a tool for knowledge sharing in organisations is gaining increasing recognition (Levy, 2009; Von Krogh, 2012), where social media are described as computer-mediated tools that allow people to create, share or exchange information, ideas and media in virtual communities and networks (Kaplan \& Haenlein, 2010). According to Alberghini, Cricelli, and Grimaldi (2014), the informality of social media can help employees fulfil their knowledge tasks and objectives, and in many ways, organisational applications of social media are close to some of the ideal principles of KM, which include the unrestricted sharing of knowledge, information and data (Razmerita, Kirchner, \& Nabeth, 2014). The application of these technologies within the workplaces of organisations to facilitate workrelated communication and collaboration is increasingly referred to as enterprise social networking (Friedman, Burns, \& Cao, 2014; Richter \& Riemer, 2013). Their use is gaining in popularity and they have been identified as beneficial to the performance and competitive advantage of organisations (Leftheriotis \& Giannakos, 2014; Leonardi, Huysman, \& Steinfield, 2013). Social media and enterprise social networking (ESN) tools bear many, similar characteristics to a $\mathrm{KM}$ technique known as communities of practice $(\mathrm{CoP})$, described by Wenger and Snyder (2000) as groups of individuals linked together by their enthusiasm for sharing and expanding their knowledge, typically in informal settings and arrangements. According to Ardichvili, Page, and Wentling (2003), CoP are efficient tools for knowledge generation and sharing because the majority of an organisation's intellectual capital is embedded in the intangible, tacit knowledge of its people, and new knowledge can be produced and disseminated in conversations and networking activities. As social media provide many opportunities for the exchange of ideas, information and knowledge (Lewis \& Rush, 2013), this technology has particular relevance to CoP and can be used to create what is termed a virtual community of practice $(\mathrm{vCoP})$. In $\mathrm{vCoP}$, the communication and coordination of work takes place online, facilitated by social media tools, meaning that the community is relational, without reference to a specific location (Gammelgaard, 2010). vCoP are interactive environments that give their members the chance to engage with other members through a series of tools such as chats, document postings and community discussions at any time and from any place. According to Wenger (1999), CoP within organisations have been identified as a mechanism to facilitate knowledge exchange between individuals by connecting isolated and distributed pockets of expertise. L. Lee, Reinicke, Sarkar, and Anderson (2015) see vCoP as offering a way of interacting with a wider range of colleagues, and vCoP in business have been shown to be effective in improving knowledge sharing and reducing professional and structural isolation (Barnett, Jones, Bennett, Iverson, \& Bonney, 2012). According to Annabi and McGann (2013, p. 14), the use of ESN in vCoP has "tremendous strategic potential, as they inherently emphasize strong relationships, encourage social interactions and promote streamlined, widespread communication between community members". ESN tools can offer improvements to the manner in which vCoP function and can increase the level of real-time collaboration across organisations. Hoffman (2009) finds that social networks can be useful mechanisms for creating communities, and are able to support social learning. A combination of ESN applications can create an effective and convenient environment for communication and learning and can help to build community through dialogue and conversation (Gunawardena et al., 2009).

According to Levy (2009), the rise of Web 2.0, and social media in particular, has brought a new wave of technologies that should be adopted in KM practice. Essentially Web 2.0 is now 
a collection of social software that supports group interaction towards establishing communities, and creating and exchanging content (Von Krogh, 2012), and is sometimes referred to as the "social web". A number of researchers feel that Web 2.0 technologies have fundamentally altered the approach to $\mathrm{KM}$ and it has undergone a paradigm shift from a static knowledge-warehouse approach to a more dynamic communication-based or network approach (Faraj, Jarvenpaa, \& Majchrzak, 2011; Haefliger, Monteiro, Foray, \& Von Krogh, 2011). However, using social media, or ESN, for KM is at an early stage and has some way to go before it gains mainstream acceptance and recognition of its value for the management and sharing of knowledge in organisational settings (Yates \& Paquette, 2011).

According to Schneckenberg (2009), ESN support dynamic knowledge exchange, representing the genuine interests and competence domains of employees, leading to the emergence of corporate information structures through a bottom-up, almost organic approach, which has the potential to bypass the rigid bureaucracy that exists in the majority of HEIs. $\mathrm{Ng}$ and Pemberton (2013) state that the concept of CoP has been extensively examined within the corporate context and can produce many benefits for both individuals and organisations, and, according to Wiig (1999), these benefits may also apply to HEIs. However, the majority of research into using $\mathrm{CoP}$ in HEIs has been done in the context of teaching and learning, and consequently very little is known about how CoP can benefit the wider HEI organisation (Kimble, Hildreth, \& Bourdon, 2008). HEIs are rarely to the fore in the implementation of information systems for either their teaching or corporate practices and, according to Leidner and Jarvenpaa (1995), academic institutions typically lag behind businesses by about ten years in the adoption of new technologies. This is in contrast to academics themselves, who are known to be early adopters of social technologies (Eysenbach, 2011) and research community software (Lin, 2012). Given that ESN are only recently becoming commonplace in organisations, it is hardly surprising then that they have not yet gained a significant foothold in HEIs. Accordingly, there has been little research into how ESNs might be used to enable knowledge sharing in HEIs (Ortbach \& Recker, 2014).

\subsection{Research Objective}

To improve the current knowledge sharing and KM levels in HEIs, the use of ESN in vCoP is seen to have some promise. In seeking to find ways to improve staff communication, collaboration and knowledge sharing, this study sets about exploring the links between ESN and $\mathrm{CoP}$, and how they can be used to create a virtual knowledge sharing environment for staff. The formal objective of this research is to examine how enterprise social networks can enable staff knowledge sharing in virtual communities of practice in higher education. The research questions examine the antecedents for a knowledge sharing environment, the dominant problems associated with staff using ESN and participating in vCoP, the key motivations for participating, and the perceived organisational and individual benefits of a vibrant knowledge sharing environment. A conceptual model was developed from the research questions and a comprehensive review of the literature. The model focuses on how a knowledge sharing environment can be created by determining the antecedents for it and the motivators for staff to engage with it, whilst identifying the dominant problems from both an organisational and individual perspective so that they can be managed. The organisational and individual benefits are also listed as outputs from the model, which is shown in Figure 1. The conceptual model adds a level of detail to allow the research questions to be investigated in the contextual setting. The model suggests that the implementation of an ESN, and the 
promotion and support of its use in vCoP, will enable staff knowledge sharing activities, providing a number of individual and organisational benefits.

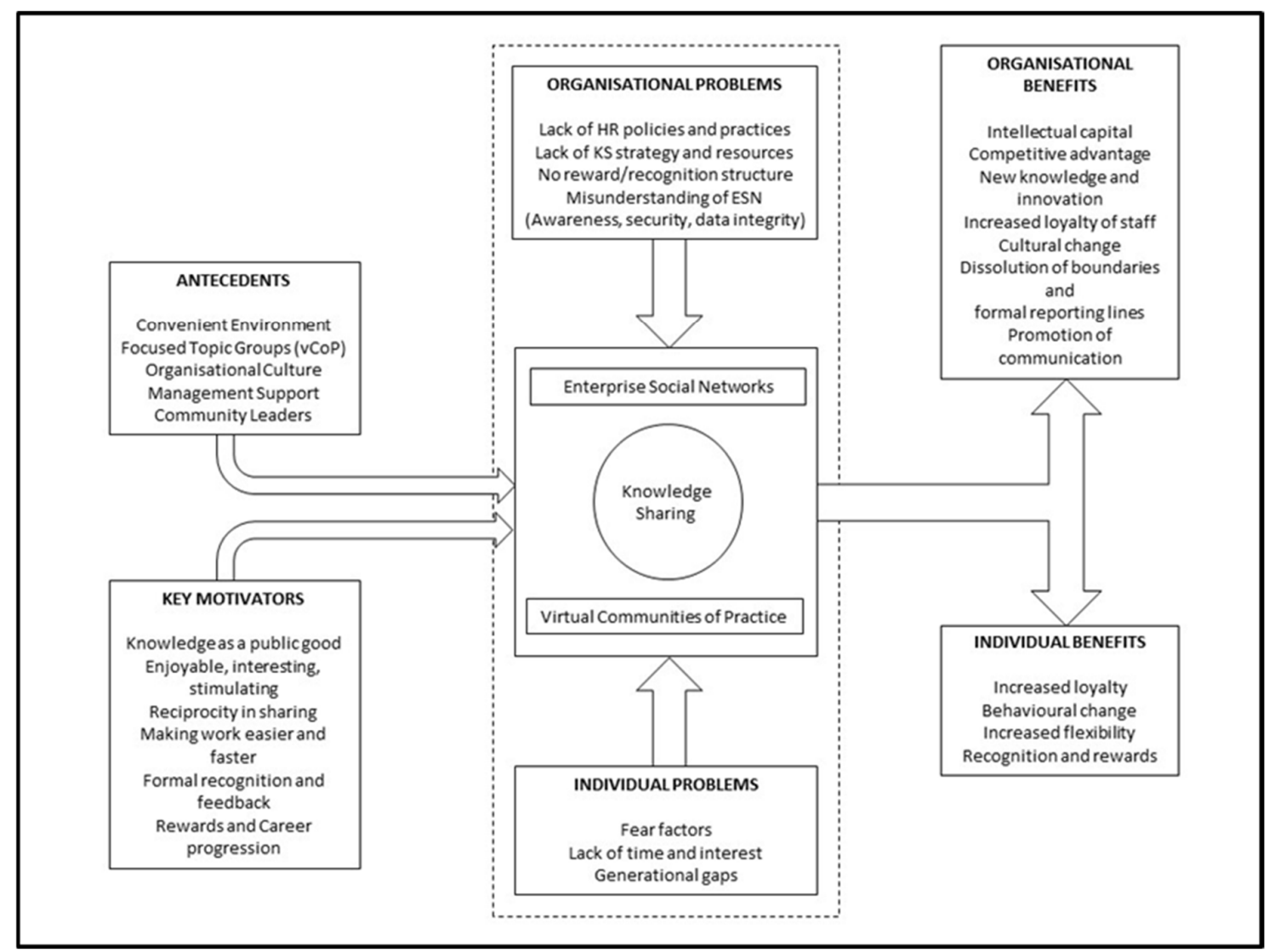

Figure 1. Conceptual Model

\section{Research Design and Implementation}

The study was undertaken as an AR project, in a public, multi-campus HEI in Ireland with approximately 6,500 students and 600 staff, over a 12 month period from September 2015 to August 2016. As the research focuses on staff knowledge sharing, the student population was not part of study. The practical aspect of the project involved the implementation of ESN tools in the organisation, specifically Microsoft's social networking tool called Yammer, and the promotion and support of these to facilitate the establishment of vCoP. Yammer is a social network that's entirely focused on a business. It facilitates group conversation and collaboration and has many similarities to familiar social media tools such as Facebook and Twitter. The lead researcher was part of the host organisation and the approach to the study embraced the researcher's place within it, fully recognising that a priori knowledge and existing values would invariably intrude upon the observation. From this understanding, it was considered that action research (AR) would be the most appropriate research strategy to adopt for the study. AR involves the active participation of the researcher and seeks to bring about change within the organisation in which it is conducted. It is an iterative process constructed with a longitudinal design to allow time to examine changes as iterations of the research progress (Baum, MacDougall, \& Smith, 2006). The AR project engaged three cycles that followed a process of Diagnosing, Action Planning, Action Taking, Evaluating and Specifying Learning, illustrated in Figure 2, and adapted from a model developed by Susman and Evered 
(1978). The project involved the creation of a Communities Portal and the use of ESN to facilitate the establishment and operation of $\mathrm{vCoP}$. The portal acts as a collection point for all of the $\mathrm{vCoP}$ in the organisation, and allows users to see what communities are active, join communities or create new ones.

Cycle 1 of the AR project was concerned with the technical establishment of the knowledge sharing environment and setup of a number of vCoP. Yammer has a feature called Groups that directly facilitates the hosting of communities online and provides an environment where they can have conversations, share files, post comments, etc. These features make it a suitable tool to support vCoP and it was selected for this project on that basis. Following an exploratory process, a number of vCoP were setup as Yammer Groups in conjunction with community leaders - staff members who had expressed interest in establishing communities. Training on $\mathrm{CoP}$ and Yammer was provided for communities, including specialist training for community leaders. As the number of users and activity on Yammer increased, a number of ESN champions were identified. These are typically highly active users who are immediately comfortable with using such systems and are seen as crucial to stimulate its growth and attract more users. These users were engaged in order to create a more formal recognition for their role and to empower them to promote the ESN in the organisation.

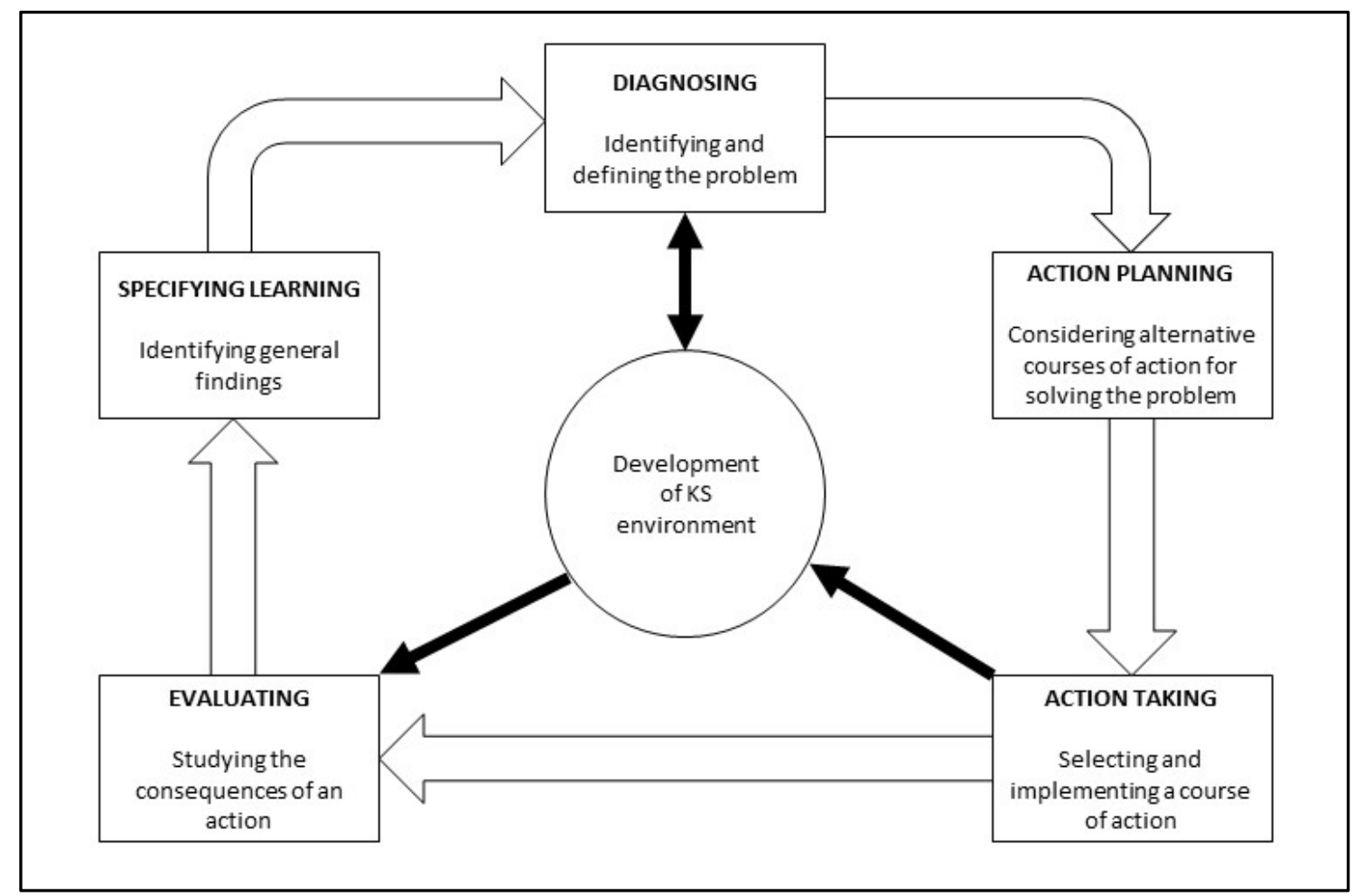

Figure 2. Phases of the AR Design

Cycles 2 and 3 of the AR project produced further packages of interventions which were based on the evaluations of the interventions carried out in the previous cycles. Both of these cycles focused on growing the user base on the ESN, fostering the development of the established $\mathrm{vCoP}$ and promoting the establishment of additional $\mathrm{vCoP}$. A number of initiatives to increase the number of Yammer users were introduced, such as providing additional functionality external to $\mathrm{vCoP}$, such as support groups, working groups, department groups, and 
information feeds. This led to a number of groups being established on Yammer that might not be considered as $\mathrm{CoP}$, such as department groups and academic course groups, with a number of others established for particular purposes, such as organising events and conferences, which could be considered as project groups. The establishment of this type of group is considered important to the long-term viability of the ESN as they engage staff who might not otherwise have had a reason to use the platform. Awareness campaigns were conducted during both cycles, and these included mass emails, advertisements on information portals and digital signage; Webinars and live training sessions.

\subsection{Data Collection and Analysis}

The study itself is qualitative in nature and the primary data collection methods used were focus groups for Cycle 1 and semi-structured interviews for Cycles 2 and 3. The strategy employed for the data collection was to use the focus groups to prove the validity of the key themes for the data collection (Table 1), and to use the data from the focus groups to develop a refined set of questions for the semi-structured interviews. Focus group meetings were combined with training for new $\mathrm{vCoP}$ and the groups were therefore representative of the membership of those communities. This proved a useful way to engage with a significant portion of the Yammer user base at an early stage, and the interaction between group members provided rich data.

\begin{tabular}{|l|l|}
\hline Research Theme & Focus Group and Interview Topics \\
\hline Knowledge Sharing & $\begin{array}{l}\text { Current levels } \\
\text { Willingness and desire to share knowledge } \\
\text { Perceived barriers to sharing knowledge } \\
\text { Perceived advantages of sharing knowledge }\end{array}$ \\
\hline Communities of Practice & $\begin{array}{l}\text { Awareness of concepts } \\
\text { Awareness and examples of existing communities } \\
\text { Perceived usefulness of communities }\end{array}$ \\
\hline $\begin{array}{l}\text { Enterprise Social } \\
\text { Networks }\end{array}$ & $\begin{array}{l}\text { Usefulness of enterprise social networks } \\
\text { Trust and security issues } \\
\text { Barriers to using enterprise social networks }\end{array}$ \\
\hline
\end{tabular}

Table 1. Focus Group and Interview Topics

The strategy worked well in practice and the themes were managed through a logical progression from the focus groups, and improved on for the interviews, so that they became close to a natural conversation, providing for further sources of rich data. In selecting 30 subjects for interview, a deliberate effort was made to achieve a sample that was representative of the target population, whilst including all stakeholders. This was achieved by using a combination of stratified and purposeful sampling to ensure a valid mix of faculty and staff, management and non-management subjects, and Yammer users and non-users. According to Marshall (1996), the most common sampling technique for qualitative studies is judgement or purposeful sampling, where the researcher actively selects the most productive sample to answer the research questions. Reflective journaling was used extensively throughout the AR cycles in order to capture interpretations of the interventions for each cycle, and also to capture informal conversations, observations, and anything else to do with the project. The content of a number of conversation threads from the ESN was also analysed to determine the depth of engagement of staff with particular communities. 


\section{Findings}

In the analysis of the overall data set, the conceptual model and associated research questions were used as a focus, and the findings are presented in the context of these (Table 2). Every aspect of the conceptual model presented in the data, and the findings confirm the model.

\begin{tabular}{|c|l|}
\hline No. & Finding \\
\hline 1. & Organisational culture and structure are major barriers to staff knowledge sharing. \\
\hline 2. & The existence of a divide between faculty and staff inhibits collaboration between them in vCoP. \\
\hline 3. & $\begin{array}{l}\text { Management have a central role to play in shaping the knowledge sharing environment, by leading } \\
\text { change initiatives and promoting the use of ESN and vCoP as KM strategies. }\end{array}$ \\
\hline 4. & $\begin{array}{l}\text { The existence of vCoP, supported by an ESN, are essential to build a successful knowledge sharing } \\
\text { environment. }\end{array}$ \\
\hline 5. & $\begin{array}{l}\text { Community leaders and champions are pivotal to the success of vCoP and the ESN, because they are } \\
\text { instrumental in helping the user base reach a critical mass. }\end{array}$ \\
\hline 6. & $\begin{array}{l}\text { Staff must be suitably motivated to participate in the knowledge sharing environment. Motivation is } \\
\text { heavily influenced by the prevalent culture, and a change in culture may impact motivation. }\end{array}$ \\
\hline 7. & $\begin{array}{l}\text { The perceived organisational and individual benefits indicate that the development of a knowledge } \\
\text { sharing environment should be a priority for management and reflected in organisational strategy. }\end{array}$ \\
\hline
\end{tabular}

Table 2. Summary of Key Findings

\subsection{Antecedents}

The findings indicate that the willingness of staff to share knowledge and participate in ESN and $\mathrm{vCoP}$ is influenced by a number of factors, almost all of which are inexorably linked to the culture of the organisation. This organisational culture in turn is influenced by a number of factors over time such as the structure and hierarchy, the attitudes and actions of management, and the organisational strategy. The findings indicate that management has an important role to play in helping to change the culture through developing and implementing organisational strategies that stimulate an active knowledge sharing environment. However, attempts by management to gain control of communities that are viewed as successful was described as a potential problem, and any such efforts should be resisted. This indicates that all CoP should have a clear terms of reference that defines what the community is for and what the expected outcomes and deliverables are, and that this is fully understood and acknowledged by all stakeholders, including management. Structured training should be available for communities during a facilitated start-up phase, and this phase should include face-to-face kick-off meetings. This highlights the need for the development of a blueprint for the creation of CoP, detailing the steps involved for community leaders and members, including things like how to organise kick-off meetings.

\subsection{Organisational and Individual Problems}

The structure of the organisation was identified as a major impediment to the development of a knowledge sharing environment, and the size and geographical dispersion of the organisation was also highlighted as problematic. The strongest individual barrier that presented in the data was time, the most cited reason for lack of participation. This applies both to academics, who face an ever increasing teaching workload, and support staff who feel that they are under resourced to adequately provide the required levels of service. Fear factors 
are also prevalent, highlighted by a number of interviewees discussing fear and trust issues as inhibitors to participation. Some described a lack of understanding of the nature of social media tools by their managers as an inhibitor, fearing that management would not understand why a member of staff would want to participate in a CoP that was not part of their cognitive domain: The attitudes of staff towards social media and the terminology used to describe the tools, such as ESN, also presented as barriers to use. Many staff see social media as something that should only be used outside of work and could not see any application for it in the workplace. The terms used to describe it, such as 'social media' and 'enterprise social networks' are problematic, either suggesting applications for frivolously chatting in the first instance, or meaning nothing very much at all in the second.

\subsection{Key Motivators}

Although most staff are motivated to participate and recognise both the individual and organisational benefits, in many cases they are either unable or unwilling to break free of the boundaries that the organisational culture places around them. The study findings indicate that in some cases, staff will participate in the knowledge sharing environment and share knowledge willingly and freely if a convenient (online) and meaningful environment is created for them to do so, and they are suitably motivated. The presence of vCoP in this environment is crucial as a motivation for participation as these can help to break down the structural and cultural boundaries that inhibit knowledge sharing. In order to sustain the development of $\mathrm{vCoP}$ and build vibrant communities that will appeal to members and attract new participants, the roles of community leaders and ESN champions are vital.

A number of interviewees felt that staff of a certain personality type are more inclined to openly share knowledge with, or to seek knowledge from others, and that the activities of these people have a positive effect on the development of CoP. This supports the idea of those that see knowledge as a public good (De Long \& Fahey, 2000; Hislop, 2013; McLure \& Faraj, 2000), and are motivated to share knowledge with others. Therefore, identifying people in the organisation who have these personality traits, and may have not yet joined the ESN, but who might be willing to participate and act as ESN ambassadors, is an important future intervention to stimulate the growth of CoP. Staff are motivated to use ESN and participate in $\mathrm{vCoP}$ if they either find their engagement to be enjoyable, interesting or stimulating, or if they can derive other benefits from participation, such as making their working lives easier or deriving some rewards in terms of recognition or career progression. The possibility of reducing workload is a strong motivational factor and many interviewees spoke about the opportunities that $\mathrm{CoP}$ presented for not having to reinvent the wheel.

\subsection{Organisational and Individual Benefits}

All of the interviewees were of the opinion that both the use of ESN and a CoP model would be of significant benefit, both to themselves in their jobs and personal development, and to the organisation. Much of the commentary was aspirational in nature and spoke about a desire for change in the culture that might arise from the establishment of an active and vibrant knowledge sharing environment. However, a number of more tangible organisational benefits were also elucidated, such as the possibility for CoP to break down the social divides and eliminate the siloes in the organisation. Many interviewees had practical examples of CoP that they might like to form that may provide considerable organisational and individual benefits. For example, it appears that new staff find it particularly difficult to engage with the organisation, and limited training opportunities are provided, suggesting a need for a Human 
Resources backed CoP to provide an on-boarding and mentoring environment for new staff. A perceived benefit that was particularly prevalent amongst support staff was CoP participation helping them to feel more a part of the organisation. Many of them feel a sense of detachment from the organisation and this is highlighted by the commentary on the divide between academic and support staff. The benefits of having ready access to knowledge both through vCoP and the ESN also drew some commentary. Yammer is seen as a significant way in which to enhance communications, providing an opportunity to communicate with people who would not normally meet on a day to day basis, and this is a particular benefit for multicampus HEIs which may have departments and faculties spread across multiple sites. A further theme that emerged from the data was the sense of being able to use CoP as a vehicle to get things done within the organisation. It was felt that both individual and group initiatives could be achievable with the support and promotion by communities.

\section{Discussion}

The findings are highly interdependent and heavily influence each other (Figure 3). For example, according to Schein (2010), organisational culture and leadership are two sides of the same coin and neither can be really understood by itself. Therefore, although the themes of the key findings are discussed independently, there is a considerable amount of overlap between them. The findings are critically assessed in light of the earlier reviews of the source literature using the connections and interdependencies between them to develop the study's conclusions.

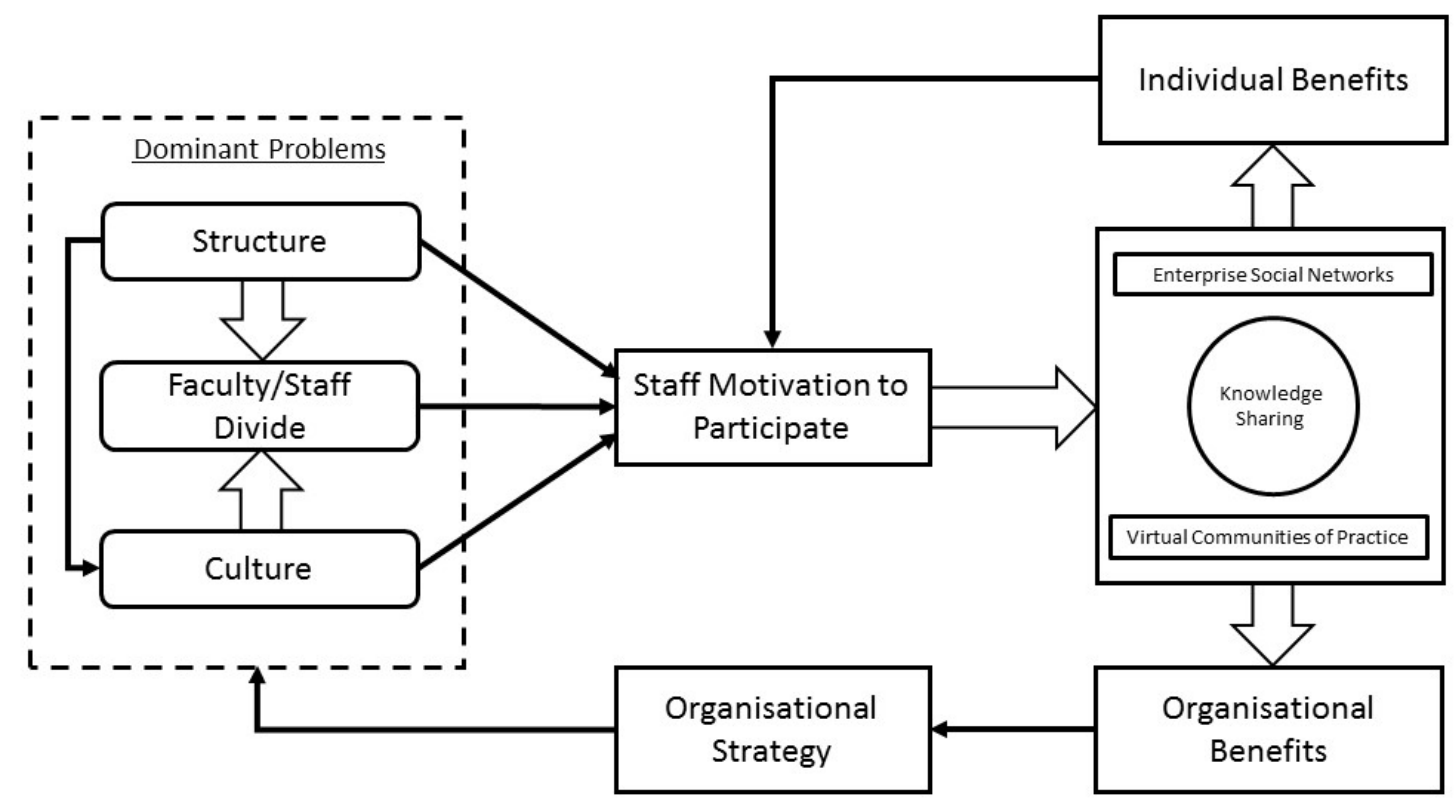

Figure 3. Interdependencies of Findings

\subsection{Organisational Culture and Structure}

The study findings indicate that organisational culture has a complex and crucial relationship with the knowledge sharing activities of the organisation. The link between organisational culture and knowledge sharing, and specifically the willingness of staff to participate, has been the subject of much research in the KM field (e.g. Annabi \& McGann, 2013; DiMicco et al., 2008). It is generally argued that organisational culture can significantly influence knowledge 
sharing activities and according to Hislop (2013), most of these studies suggest that it can have a positive influence on knowledge sharing. However, a number of studies highlight the negative impacts that certain organisational cultures can have on knowledge sharing activities (Lam, 2005; Rai, 2011; Suppiah \& Singh Sandhu, 2011). Alavi, Kayworth, and Leidner (2005) suggest that positive cultural values such as openness, sharing and trust will lead to positive behaviours, and negative values will lead to dysfunctional behaviours. Therefore, if an organisation wishes to develop an active and useful knowledge sharing environment in which staff openly and freely collaborate and share knowledge, it is necessary for it to understand what type of an organisational culture it has. Although this may sound like a straightforward process, in practice it can be difficult to achieve, and Ogbonna and Harris (1998) conclude that management's view of what the culture is may not be shared by other members of the organisation.

There are a number of organisational culture types identified in the literature, such as Cameron and Quinn's (2005) widely cited classification of clan, adhocracy, market and hierarchy cultures, and in examining the links between leadership and organisational culture, Bass and Avolio (1993) usefully classify organisational culture into two distinct types: transactional and transformational. A transactional organisational culture can be closely linked to a hierarchical organisational culture type and these are rooted in formal organisational structures, processes and procedures, and tend to dominate public sector organisations and HEIs. According to Bass and Avolio (1993), a transactional culture focuses on everything in terms of explicit and implicit contractual relationships, and is characterised by staff with short-term interests working as independently as possible from colleagues, and having little identification with the mission and vision of the organisation. This results in a mechanistic organisation with much attention to controls, directions and standard operating procedures. Little gets done that is not as a consequence of formal agreements, and risk-taking is avoided, resulting in little or slow progress and change. According to Denison and Mishra (1995), this leads to a high degree of separation between management and staff, and where open and frank discussions between levels in the hierarchy are discouraged. De Long and Fahey (2000) maintain that this helps to create a context for communication that undermines effective knowledge sharing. The findings from this study clearly demonstrate that the organisation is firmly in the hierarchy quadrant of the Cameron and Quinn (2005) model with a wholly transactional organisational culture.

The conceptual model highlighted the necessity of having an appropriate organisational culture as an antecedent of a successful and active knowledge sharing environment. Annabi and McGann (2013) conclude that organisations must adopt a knowledge sharing culture that recognizes the value of informal knowledge sharing in vCoP using social media tools, and Zboralski (2009) highlights the need for having an encouraging environment and culture where knowledge sharing is promoted. The existence of a transactional culture as the dominant culture in the organisation suggests that the development of a successful knowledge sharing environment is not possible. Although the AR project led to the creation of a number of $\mathrm{vCoP}$ and some growth and sustained use of the ESN, this could not be extrapolated as a completely successful implementation across the organisation. For this to happen, the organisational culture needs to move towards what Bass and Avolio (1993) describe as a transformational culture, where employees go beyond their self-interests or expected rewards for the good of the organisation. Such organisations are flexible, adaptive, dynamic, and 
informal, and place much emphasis on the potential of its individual employees to grow and improve.

Rigid organisational structures that promote transactional cultures tend to be the norm in public sector HEIs and have been in existence in the same format with little change since their foundation, and encourage the creation of silos and lead to staff isolation (Bannister, 2001; Tippins, 2003). Organisations that can create an open and transparent culture help to make employees feel empowered and have a voice, making them feel more connected and loyal to the organisation (Lok \& Crawford, 2004; Trice \& Beyer, 1993). Much HEI strategic vision and rhetoric is given to the desire of such organisations to be dynamic in operation and responsive to the needs of their markets and customers. However, it is not feasible for large public sector HEIs to suddenly develop loose, decentralized, flat structures that are common in innovative and creative private sector firms, not least because such organisational structures are largely mandated by government policy and applied at a national level (McCarthy, 2014). Therefore, in accepting that organisational structures cannot be readily changed to create the conditions that would help the development of a transformational culture, we must look for other ways within the existing structures for this to happen. For example, a number of authors argue that managing cultural change is difficult and that a natural change of culture is more likely, taking place through the socialization of new staff over time (Pascale, 1985; Sathe, 1983), and Ogbonna and Harris (1998) argue that attempts at culture change should focus on means of perpetuations such as communications. It is also possible for culture change to be led through a bottom-up approach, where pockets of excellence and influence can have a significant impact on the overall behaviour of the organisation, through individuals described by Pascale and Sternin (2005, p. 72) as "positive deviants", and these can be likened to the roles of community leaders and ESN champions.

\subsection{Academic Staff Divide}

The academic staff divide contributes to the fragmentation of the organisation and exacerbates a culture that limits opportunities for staff interaction, collaboration and knowledge sharing. However, the study found that a number of vCoP have both faculty and staff membership, and both groups seem quite happy to freely share knowledge and collaborate within their $\mathrm{vCoP}$. This indicates that the knowledge sharing environment can provide a means for faculty and staff to collaborate on areas of common interest and help to bridge the divide that exists between them. For this to happen in a meaningful way, and on a scale that can influence a shift towards a transformational culture, it requires management to recognize the existence of the academic staff divide and its impact on knowledge sharing and collaborative activities. According to Florenthal and Tolstikov-Mast (2012), the culture of a HEI has a significant influence on the overall education experience of its students, and a strong sense of community amongst staff is critical to achieving a positive organisational culture. This sense of community can only be created in the presence of strong working relations between faculty and staff. The choice then for management is to find opportunities to get faculty and staff to work together in meaningful ways or to perpetuate a divide that simply does not help students or the organisation in any way. The study findings indicate that when the right collaboration opportunities are presented to faculty and staff, they will collaborate and communicate with each other. This suggests that having a knowledge sharing environment complete with vCoP as a central knowledge management technique, and supported by ESN, should be at the heart of organisational strategies that seek to improve staff communication and knowledge sharing in order to drive organisational efficiencies. 


\subsection{The Role of Management}

The attitudes, actions and behaviours of leaders and managers have an important role to play in the context of knowledge sharing in HEIs. In organisations in general, Bircham-Connolly, Corner, and Bowden (2005) suggest that leadership has a pivotal role to play in promoting and cultivating knowledge sharing behaviour, mainly by providing opportunities and managing the processes for staff to share and transfer their knowledge. According to S. Wang and Noe (2010), when management is supportive of knowledge sharing, employees perceive that a knowledge sharing culture is prevalent, indicating that leadership is highly significant in this regard. According to Wi (2015), management participation is crucial for successful collaboration to happen within organisations. Leaders are aware that they should engage with employees, and particularly through social and digital channels, but they tend not to. There are a number of reasons for this including fear that such engagement would result in a weakening of power relations, reducing their ability to control and command. Wi (2015) maintains that collaboration depends on trust and leaders must learn how to trust their staff on platforms such as an ESN, although the tools themselves are not as important as management's understanding of the purpose and nature of the tools. Using platforms such as ESN requires organisational change, and that change generally needs to be led by management. This requires visionary leadership, defined strategic objectives, and a commitment to lead the organisation through the necessary change. Kezar and Eckel (2002, p. 457) found a strong relationship between organisational change and culture in the context of higher education, and that leaders who are acting as organisational change agents must become "cultural outsiders" in order to understand their own cultures and their impact on change initiatives, through examination and reflection. Fidelman (2012, p. 3.6), refers to the change in culture as organisations becoming "social businesses", and this requires a new strategy, which takes "time, persuasion, planning, teamwork, and measurable goals". It is suggested that this process is quite difficult for bureaucratic and hierarchical organisations, of which HEIs are typical examples. However, once the value to the organisation has been recognized, a vision for a knowledge sharing enterprise and the expected outcomes can be provided. Following this, a community management plan can be established where the people, processes, resources and technology are provided to support the vision. Lastly, the execution of the plan requires the identification of leaders and champions within the organisation who will help to promote the vision and the changes associated with it. According to Zboralski (2009, p. 94), establishing a "knowledge management friendly atmosphere", which includes the active promotion of $\mathrm{CoP}$, will increase employees' awareness of the need to share knowledge and will encourage CoP participation.

The findings imply that middle management has a pivotal role to play in the development of knowledge sharing initiatives and their attitudes and behaviour will have a direct impact on staff participation. This is supported by Huy (2002), who investigated the emotional commitment to organisational change by middle managers, and Ogbonna and Wilkinson (2003), who investigated the impact of cultural change initiatives on middle managers. It is suggested that managers with creative abilities are more likely to recognise the potential of ESN and vCoP and promote their use within their own departments and amongst their staff. In contrast, strictly operational managers are more likely to see the ESN as another IT tool that has to be negotiated and could potentially hinder participation through discouragement and negativity. Having an active executive sponsor can go some way towards mitigating against 
this situation, and increasing awareness through training and information sessions for middle managers can also help in this regard.

\subsection{Virtual Communities of Practice}

According to Bolisani and Scarso (2014), the concept of CoP as a KM technique has been widely applied by companies in practice in order to promote knowledge sharing amongst employees to improve business performance. The study findings indicate that vCoP can and do emerge from the bottom-up, through the efforts of individuals who are interested in particular subjects and who seek out colleagues with similar interests in order to share their knowledge and experiences and learn from each other. $\mathrm{vCoP}$ are also more likely to emerge, and in greater numbers, because of the relative simplicity of their creation, facilitated by the ESN platform, compared to traditional CoP. The findings also suggest that for genuine social interaction to take place in $\mathrm{vCoP}$, they need to be relevant, purposeful and appealing in order to stimulate a real desire or need to engage. The knowledge sharing environment also needs to be in tune with the ways people interact on the social web, which embody the underlying open ethos that people enjoy, rather than be a forced environment for conversations. To facilitate this, the selection of the ESN is important, and it must provide an interface and functionality that people expect from a social media platform. The provision of a familiar tool has dual benefits of making the system more attractive to users, and reducing the need for extensive training on the platform itself. It does not, however, reduce the need for training in vCoP, which is essential to provide members with a complete understanding of what communities are, how they operate, and to provide a set of guidelines or a framework to work within. Hislop (2013) states that CoP provide staff with a sense of collective identity and this is supported by the study findings where staff who expressed feeling a sense of detachment from the organisation felt that participation in vCoP would give them a better sense of engagement and identification with it. As CoP are based on shared professional interest and commitment rather than on projects or organisational position (Alavi et al., 2005), they provide opportunities for staff members from different departments and disciplines to interact on areas of common interest, and importantly, provide an environment for faculty and staff to interact in ways that would otherwise most likely not arise.

\subsection{Community Leaders and Champions}

According to Borzillo, Aznar, and Schmitt (2011), community leaders are specific people who undertake organising roles with the objective of developing and sustaining the community. In many cases, they are the founders of particular $\mathrm{CoP}$ and are generally the driving force behind them. The vitality of $\mathrm{CoP}$ are very dependent on the interest and commitment of their leaders, and communities that do not have dedicated leaders are bound to fail. Zboralski (2009) states that community leaders are responsible for motivating other members to participate, coaching new members, and organising and advertising community events, and the more attention that is paid to these tasks, the more intensive the activity of the CoP will be. However, it is the most demanding and time-intensive role in a community and community leaders must be prepared to nurture the development of a $\mathrm{CoP}$, particularly if they are instrumental in establishing them. The study findings show that during the early growth phase of the ESN, the conversations were dominated by a number of individuals who use the technology freely and enthusiastically, and are generally comfortable using social media. This is supported by Hart (2015) and consistent with Rogers (1995) diffusion of innovations theory. Most of them became members of more than one $\mathrm{vCoP}$ on the ESN and participated in discussions in all of the 
communities that they were in. The findings also suggest that ESN champions have a distinct personality type that inclines them to openly share knowledge with, or to seek knowledge from others, and that the activities of these people have a positive effect on the development of CoP. They take a professional pride in helping people through sharing knowledge and this finding supports the idea that some individuals see knowledge as a public good and will freely share it (Hislop, 2013; McLure Wasko \& Faraj, 2005). The identification of these individuals is central to opening up the ESN to everyone in the organisation as they, in conjunction with community leaders, keep conversations and activity at levels that are necessary to attract other users and reach a critical mass for sustainability. The role of champions should be clearly identified in an ESN strategy and they should be given adequate supports to fulfil their roles, which may simply be providing them with adequate equipment and connectivity to ensure that they have ready access to the ESN, and training in their role as an ESN champion.

\subsection{Staff Motivation}

In order to successfully manage the development and growth of the knowledge sharing environment, it is necessary to understand both what motivates the majority of the staff population to participate and what prevents them from participating. Therefore, motivations for participation must be examined in conjunction with barriers to participation. The study findings indicate that staff are motivated to participate if they either find their engagement to be enjoyable, interesting or stimulating, or if they can derive other benefits from participation, such as making their working lives easier or gaining some rewards in terms of recognition or career progression. In addition to the cultural barriers that inhibit many staff from participating, there are also a number of individual barriers that emerged from the study, some of which were predicted in the conceptual model and some not. The main individual barriers to participation that present in the study, such as fear factors, lack of time and the age profile of staff, have already been explored to some degree in the literature. One unexpected finding is that the terminology used to describe the online tools (ESN and social media) can be problematic and puts many staff off participation because they associate social media with frivolity and activities that should not be associated with work. Indeed, many staff see social media as something that should only be used outside of work and do not see any application for it in the workplace. Many participants also had no concept of what enterprise social networking actually is, much less envisage it as a collaboration platform that could be used in the workplace. Addressing the problem requires organisations who are developing knowledge sharing platforms based on ESN technology, to consider a re-branding of the ESN with terminology that is more closely associated with community activity. Staff should also be educated about the purpose and use of ESN in the organisation through awareness and training programmes that emphasise the professional aspects of these applications.

\subsection{Perceived Benefits}

The study findings show that there is a general perception that participating in the knowledge sharing environment will result in benefits to both the individual and the organisation. The findings also indicate that there is a perception that a successful knowledge sharing environment can positively influence the organisational culture and lead to a more open, creative and sharing organisation, with an increased sense of belonging and loyalty engendered through participation. However, it should be noted that these are perceived benefits and have not been measured as actual benefits that have been derived from participation. Although, individual benefits can be empirically explored, organisational 
benefits, such as increased intellectual capital and improved performance, can be difficult to quantify (López-Nicolás \& Meroño-Cerdán, 2011; Z. Wang \& Wang, 2012).

CoP can deliver different benefits to different types of organisation. For example, Lesser and Storck (2001) suggest that they have the potential to overcome many of the inherent problems for slow-moving, hierarchical organisations that have to exist in a fast-moving, virtual economy. They are also an effective way for organisations to share knowledge outside of traditional structural boundaries. This suggests that CoP would be a beneficial KM technique for public sector organisations such as HEIs to adopt. However, because communities don't appear on organisational charts and balance sheets, they can only be considered as a hidden asset, and this presents a difficulty in determining how exactly they deliver value. This may also present a problem for highly risk-averse organisations, such as public sector bodies, who generally need to be able to quantify a return before making an investment. Rather than attempting to quantify the benefits of a CoP model, a better approach may be to for the organisation to develop an understanding of how CoP can create value. Lesser and Storck (2001) suggest that thinking of communities as engines for the development of social capital would be helpful, and argue that the development of social capital in CoP leads to behavioural change, resulting in greater knowledge sharing, and this in turn can positively influence organisational performance.

Similar to CoP, the benefits of ESN implementation and use for organisations can be difficult to quantify in terms of specific deliverables and direct value. However, there is a growing body of research that argues that ESN can bring many and significant benefits to the organisation through increased communication and knowledge sharing, and increased social capital (Davison, Ou, Martinsons, Zhao, \& Du, 2014; Leonardi \& Meyer, 2015). Some recent empirical research furthers this by making positive associations between ESN use and employee performance (Riemer, Finke, \& Hovorka, 2015), and finding that ESN can help to overcome some of the barriers to organisational knowledge sharing, such as motivation, and developing and maintaining social ties (Fulk \& Yuan, 2013).

For HEIs, the use of ESN is seen to have the potential to promote communication amongst staff and encourage interaction across functional areas, and between faculty and staff (Schneckenberg, 2009; Zhao \& Kemp, 2013). The study found considerable evidence to support this in a number of vCoP that have both faculty and staff members, where there was open discussion that was independent of boundary and reporting lines. A potential benefit that emerged from the study was the opportunity to use ESN and $\mathrm{vCoP}$ as on-boarding tools to support new staff. A number of participants discussed the lack of support available for new staff, especially faculty, and felt that participating in relevant online communities would allow them to assimilate into the organisation more efficiently. In addition, the availability of the ESN as a communications platform would provide them with a space to seek information to help them in their new roles, allowing them a means to tap into the existing organisational knowledge base. The use of ESN in this fashion has been investigated by Leidner, Koch, and Gonzalez (2010, p. 229), who found that they can immediately increase the sense of cultural belonging to the organisation, make the environment of entry-level workers exciting, and

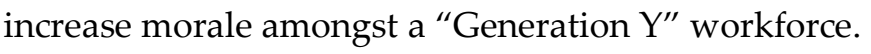




\section{Conclusion}

There is a growing awareness amongst practitioners and researchers that the implementation of social media in organisations has given a new impetus to KM. However, limited research has been conducted on applications of social media for organisational knowledge sharing, and especially in higher education contexts. In examining how ESN tools can enable staff knowledge sharing in $\mathrm{vCoP}$ in a HEI, this research has produced a number of findings informing both theory and practice, and which can be used as a basis for further research. One of the outcomes from the AR project was the development of a package of interventions to continue to grow the ESN user base and encourage the establishment of more communities, which is necessary to ensure the continuation of the practical element of the project (Table 3). Implications for practice are presented in Table 4, and suggestions for further research in Table 5.

\begin{tabular}{|c|c|}
\hline No. & Intervention \\
\hline 1 & Develop new terminology to replace ESN and 'social media'. \\
\hline 2 & $\begin{array}{l}\text { Expand communities' model to include communities of interest, communities of } \\
\text { place (e.g. a campus community), and external communities. }\end{array}$ \\
\hline 3 & Develop case studies of successful CoP to promote CoP model. \\
\hline 4 & Establish metrics to determine the health and success of communities. \\
\hline 5 & $\begin{array}{l}\text { Develop a best practice guide for ESN users to help establish it as part of daily } \\
\text { work routines. }\end{array}$ \\
\hline 6 & $\begin{array}{l}\text { Devise strategies to increase participation rates in CoP by moving members along } \\
\text { the membership life cycle as per Lave and Wenger (1991). }\end{array}$ \\
\hline 7 & Develop a role/job description for an Enterprise Community Manager. \\
\hline 8 & $\begin{array}{l}\text { Work with HR to develop the ESN for social on boarding and mentoring of new } \\
\text { staff. }\end{array}$ \\
\hline 9 & $\begin{array}{l}\text { Investigate the use of Yammer as a teaching and learning tool for students in order } \\
\text { to engage more academic staff. }\end{array}$ \\
\hline 10 & $\begin{array}{l}\text { Identify staff who see knowledge as a public good, with a view to becoming ESN } \\
\text { ambassadors. }\end{array}$ \\
\hline
\end{tabular}

Table 3. Package of Interventions for ESN/vCoP Management

The main limitation of this study was the time frame available for the AR project. According to Holtzblatt, Drury, Weiss, Damianos, and Cuomo (2013), adoption of new social software in organisations can be very slow, with interactions between users, changes in work practices, and the impact on business outcomes, all taking time to emerge. In order for these 'long-tail effects' to be realised, social communities must reach a critical mass, and the impacts are only seen in large populations over long periods of time. The problem is further exacerbated in this context by the nature of the academic year, with significant periods when faculty are largely absent from campus, including a three to four week period in December/January and an eight to twelve week period from June to August. Notwithstanding the validity of the empirical testing of the conceptual model, the ability to conduct a similar AR study over a period of two, or even three, academic years, would significantly enhance the results, and would allow for the introduction of more quantitative measures, informing a mixed methods approach. 


\begin{tabular}{|l|l|}
\hline Conclusion & Implication for Practice \\
\hline $\begin{array}{l}\text { A transactional organisational culture is a } \\
\text { barrier to staff interaction, collaboration and } \\
\text { knowledge sharing. }\end{array}$ & $\begin{array}{l}\text { Organisations require a developed } \\
\text { understanding of their culture to inform } \\
\text { meaningful and achievable strategic vision } \\
\text { and goals. }\end{array}$ \\
\hline $\begin{array}{l}\text { The prevalent culture largely derives from } \\
\text { state mandated organisational structures. }\end{array}$ & $\begin{array}{l}\text { Requires a sectoral understanding of the } \\
\text { problem and a willingness at national level } \\
\text { to influence change. }\end{array}$ \\
\hline $\begin{array}{l}\text { The existence of the divide between faculty } \\
\text { and staff exacerbates the negative aspects of } \\
\text { the organisational culture. }\end{array}$ & $\begin{array}{l}\text { The existence of the divide needs to be } \\
\text { recognised and understood by management } \\
\text { if it is to be dealt with. }\end{array}$ \\
\hline $\begin{array}{l}\text { Management support is pivotal to the } \\
\text { success of KM initiatives. }\end{array}$ & $\begin{array}{l}\text { Management must understand their role in } \\
\text { KM initiatives, from facilitation to } \\
\text { participation. }\end{array}$ \\
\hline $\begin{array}{l}\text { The knowledge sharing environment must } \\
\text { be adequately designed, resourced and } \\
\text { supported. }\end{array}$ & $\begin{array}{l}\text { CoP terms of reference and generic } \\
\text { blueprints should be established, and these } \\
\text { should be bolstered by structured training. }\end{array}$ \\
\hline $\begin{array}{l}\text { For the ESN and vCoP to become } \\
\text { established, the roles of community leaders } \\
\text { and social media champions are very } \\
\text { important. }\end{array}$ & $\begin{array}{l}\text { Individuals in the organisation who exhibit } \\
\text { the traits of community leaders and social } \\
\text { media champions, should be identifies, } \\
\text { encouraged and incentivised to participate. }\end{array}$ \\
\hline $\begin{array}{l}\text { The knowledge sharing environment } \\
\text { provides opportunities for mentoring and } \\
\text { supporting new staff. }\end{array}$ & $\begin{array}{l}\text { ESN and vCoP should be looked at by HR } \\
\text { departments who are interested in the } \\
\text { efficient assimilation of new staff into the } \\
\text { organisation. }\end{array}$ \\
\hline $\begin{array}{l}\text { The terminology used to describe work- } \\
\text { based social media tools can be problematic } \\
\text { and inhibit many staff from using them. }\end{array}$ & $\begin{array}{l}\text { Those implementing ESN should be } \\
\text { cognisant of this and apply more } \\
\text { community based terminology. } \\
\text { ESN developers should investigate the } \\
\text { introduction of alternative nomenclature. }\end{array}$ \\
\hline
\end{tabular}

Table 4. Implications for Practice.

A further limitation of this research may be the generalisability of the findings outside of the subject organisation. However, the size and standing of the HEI in question, indicate that it is a valid representative sample to apply generalisability to the conclusions drawn from this study to the wider, national higher education sector. Irish HEIs in general bear many similarities to HEIs in other jurisdictions, and indeed to other public sector organisations, and the findings may be of interest to the wider higher education community and other elements of the public sector. In addition, many aspects of the conceptual model may be applied to any organisation, including in the private sector, and a number of the related findings may be of interest to practitioners undertaking similar projects. These include the development of clear terms of reference and blueprints for $\mathrm{CoP}$, and the development of structured training for both $\mathrm{CoP}$ and ESN. Some of the barriers to participation such as lack of time and fear of using social media are also not unique to HEIs, and the findings should be of interest to others who are using social media in a similar fashion. The use of ESN as a means of improving general communications within the organisation should be of practical interest to management, as should the suggestion that ESN and vCoP could be used as on-boarding and mentoring tools for new staff. The management of HEIs in particular should be concerned with the strong 
evidence uncovered for the existence of a divide between academic and other staff. The identification of the importance of management support for the establishment and use of ESN for $\mathrm{vCoP}$ and knowledge sharing also has implications for management in HEIs who wish to improve their KM capabilities.

\begin{tabular}{|l|l|}
\hline Conclusion & Opportunity for Further Research \\
\hline $\begin{array}{l}\text { The } 12 \text { month period of the AR project was } \\
\text { limiting, particularly in the HEI context. }\end{array}$ & $\begin{array}{l}\text { A longtitudinal AR study design, over two } \\
\text { or three academic years, investigating } \\
\text { similar themes. }\end{array}$ \\
\hline $\begin{array}{l}\text { The divide between faculty and staff is not } \\
\text { equally perceived by both groups. }\end{array}$ & $\begin{array}{l}\text { A balanced study approach could extend the } \\
\text { knowledge in this area, with impacts for the } \\
\text { management of HEIs. }\end{array}$ \\
\hline $\begin{array}{l}\text { The importance of management support for } \\
\text { KM initiatives has unequal perceptions } \\
\text { amongst management and staff. }\end{array}$ & $\begin{array}{l}\text { A study across a number of organisations in } \\
\text { both the public and private sectors could } \\
\text { add to the understanding of the success of } \\
\text { KM initiatives. }\end{array}$ \\
\hline $\begin{array}{l}\text { The role of transformational leaders in HEIs } \\
\text { and their ability to deliver culture change is } \\
\text { not widely recognised. }\end{array}$ & $\begin{array}{l}\text { Research examining the prevalent culture in } \\
\text { HEIs, and its relationship with leadership } \\
\text { types, would be useful for informing long- } \\
\text { term HEI strategies. }\end{array}$ \\
\hline $\begin{array}{l}\text { The organisational and individual benefits } \\
\text { derived from having a knowledge sharing } \\
\text { culture are not well understood, and often } \\
\text { vaguely stated. }\end{array}$ & $\begin{array}{l}\text { Long term, mixed-methods studies to } \\
\text { determine the organisational benefits of } \\
\text { ESN and vCoP adoption, and the individual } \\
\text { benefits of participation, are required. }\end{array}$ \\
\hline
\end{tabular}

\section{Table 5. Opportunities for Further Research}

Notwithstanding the evidence for organisational structures and geographical dispersion in a multi-campus environment presenting as barriers to knowledge sharing, there is a perception that the development of a strong knowledge sharing environment can have a positive impact on organisational culture, helping to break down social divides and eliminate silos. Studying the further development and the ongoing activities of the ESN and vCoP will help to see how this can be achieved in practice. In addition, given the extended time-frame required for achieving critical mass with the implementation of any knowledge sharing environment using ESN tools, long-term studies are required to fully understand the implications of achieving strategic goals for knowledge sharing, both in terms of the derived benefits to both the organisation and individuals, and also for the culture of the organisation.

\section{References}

Alavi, M., Kayworth, T. R., \& Leidner, D. E. (2005). An empirical examination of the influence of organizational culture on knowledge management practices. Journal of management information systems, 22(3), 191-224.

Alberghini, E., Cricelli, L., \& Grimaldi, M. (2014). A methodology to manage and monitor social media inside a company: a case study. Journal of knowledge management, 18(2), 255277.

Annabi, H., \& McGann, S. T. (2013). Social media as the missing link: Connecting communities of practice to business strategy. Journal of Organizational Computing and Electronic Commerce, 23(1-2), 56-83. 
Ardichvili, A., Page, V., \& Wentling, T. (2003). Motivation and barriers to participation in virtual knowledge-sharing communities of practice. Journal of knowledge management, 7(1), 64-77.

Bannister, F. (2001). Dismantling the silos: extracting new value from IT investments in public administration. Information Systems Journal, 11(1), 65-84.

Barnett, S., Jones, S. C., Bennett, S., Iverson, D., \& Bonney, A. (2012). General practice training and virtual communities of practice-a review of the literature. BMC family practice, 13(1), 87.

Bass, B. M., \& Avolio, B. J. (1993). Transformational leadership and organizational culture. Public administration quarterly, 1993(Spring), 112-121.

Baum, F., MacDougall, C., \& Smith, D. (2006). Participatory action research. Journal of epidemiology and community health, 60(10), 854-857.

Bircham-Connolly, H., Corner, J., \& Bowden, S. (2005). An empirical study of the impact of question structure on recipient attitude during knowledge sharing. Electronic Journal of Knowledge Management, 32(1), 1-10.

Bloom, D. (2005). Raising the Pressure: Globalisation and the Need for Higher Education Reform. In G. Jones, P. McCarney, \& M. Skolnik (Eds.), Creating Knowledge, Strengthening Nations. Toronto: University of Toronto Press.

Bolisani, E., \& Scarso, E. (2014). The place of communities of practice in knowledge management studies: a critical review. Journal of knowledge management, 18(2), 366-381.

Borzillo, S., Aznar, S., \& Schmitt, A. (2011). A journey through communities of practice: How and why members move from the periphery to the core. European Management Journal, 29(1), 25-42.

Cameron, K. S., \& Quinn, R. E. (2005). Diagnosing and Changing Organizational Culture: Based on the Competing Values Framework. New Jersey: John Wiley \& Sons.

Castleman, T., \& Allen, M. (1995). The Forgotten Workforce: Female General Staff in Higher Education. Australian Universities' Review, 38(2), 65-69.

Collinson, V., \& Cook, T. F. (2003). Learning To Share, Sharing To Learn: Fostering Organizational Learning through Teachers' Dissemination of Knowledge. Paper presented at the Annual Meeting of the American Educational Research Association, Chicago, IL, USA.

Conway, M. (2000). What's in a name? Issues for ATEM and administrators. Journal of Higher Education Policy and Management, 22(2), 199-201.

Cranfield, D. J., \& Taylor, J. (2008). Knowledge Management and Higher Education: A UK Case Study. Electronic Journal of Knowledge Management, 6(2), 85-99.

Cronin, B. (2001). Knowledge management, organizational culture and Anglo-American higher education. Journal of Information Science, 27(3), 129-137.

Davison, R. M., Ou, C. X., Martinsons, M. G., Zhao, A. Y., \& Du, R. (2014). The communicative ecology of Web 2.0 at work: Social networking in the workspace. Journal of the Association for Information Science and Technology, 65(10), 2035-2047. 
De Long, D., W, \& Fahey, L. (2000). Diagnosing cultural barriers to knowledge management. The Academy of management executive, 14(4), 113-127.

Denison, D. R., \& Mishra, A. K. (1995). Toward a theory of organizational culture and effectiveness. Organization science, 6(2), 204-223.

DiMicco, J., Millen, D. R., Geyer, W., Dugan, C., Brownholtz, B., \& Muller, M. (2008). Motivations for Social Networking at Work. Paper presented at the ACM Conference on Computer Supported Cooperative Work, San Diego, CA, USA.

Dobson, I. R. (2011). How the other half lives: university general staff today and tomorrow. Campus Review, 2012(3), 1-7.

Edvinsson, L. (2002). Corporate Longitude: What You Need to Know to Navigate the Knowledge Economy. London: Pearson Education.

Eysenbach, G. (2011). Can tweets predict citations? Metrics of social impact based on Twitter and correlation with traditional metrics of scientific impact. Journal of medical Internet research, 13(4), e123.

Faraj, S., Jarvenpaa, S. L., \& Majchrzak, A. (2011). Knowledge collaboration in online communities. Organization science, 22(5), 1224-1239.

Fidelman, M. (2012). Socialized!: How the Most Successful Businesses Harness the Power of Social. Brookline, MA, USA: Bibliomotion, Inc.

Florenthal, B., \& Tolstikov-Mast, Y. (2012). Organizational culture: Comparing faculty and staff perspectives. Journal of Higher Education Theory and Practice, 12(6), 81.

Friedman, B. D., Burns, M. J., \& Cao, J. (2014). Enterprise Social Networking Data Analytics Within Alcatel-Lucent. Bell Labs Technical Journal, 18(4), 89-109.

Fulk, J., \& Yuan, Y. C. (2013). Location, motivation, and social capitalization via enterprise social networking. Journal of Computer-Mediated Communication, 19(1), 20-37.

Fullwood, R., Rowley, J., \& Delbridge, R. (2013). Knowledge sharing amongst academics in UK universities. Journal of knowledge management, 17(1), 123-136.

Gammelgaard, J. (2010). Knowledge retrieval through virtual communities of practice. Behaviour \& Information Technology, 29(4), 349-362.

Gibbs, G. (1988). Learning by Doing: A Guide to Teaching and Learning Methods. London: Further Education Unit.

Goffee, R., \& Jones, G. (2015). Why Should Anyone Work Here? - What it Takes to Create an Authentic Organisation. Boston, MA, USA: Harvard Business Press.

Gunawardena, C. N., Hermans, M. B., Sanchez, D., Richmond, C., Bohley, M., \& Tuttle, R. (2009). A theoretical framework for building online communities of practice with social networking tools. Educational Media International, 46(1), 3-16.

Haefliger, S., Monteiro, E., Foray, D., \& Von Krogh, G. (2011). Social software and strategy. Long Range Planning, 44(5), 297-316.

Hart, J. (2015). Modern Workplace Learning: A Resource Book for LED. Self-published: Centre for Learning \& Performance Technologies. 
Hislop, D. (2013). Knowledge Management in Organizations: A Critical Introduction. Oxford: Oxford University Press.

Hoffman, E. (2009). Evaluating social networking tools for distance learning. Paper presented at the TCC Worldwide Online Conference, Hawaii, USA.

Holtzblatt, L., Drury, J. L., Weiss, D., Damianos, L. E., \& Cuomo, D. (2013). Evaluating the uses and benefits of an enterprise social media platform. Journal of Social Media for Organizations, 1(1), 1.

Huy, Q. N. (2002). Emotional balancing of organizational continuity and radical change: The contribution of middle managers. Administrative science quarterly, 47(1), 31-69.

Jasper, M. A. (2005). Using reflective writing within research. Journal of research in nursing, 10(3), 247-260.

Kaplan, A. M., \& Haenlein, M. (2010). Users of the world, unite! The challenges and opportunities of Social Media. Business horizons, 53(1), 59-68.

Kezar, A., \& Eckel, P. D. (2002). The effect of institutional culture on change strategies in higher education: Universal principles or culturally responsive concepts? The Journal of Higher Education, 73(4), 435-460.

Kidwell, J. J., Vander Linde, K. M., \& Johnson, S. L. (2000). Knowledge Management Practices Applying Corporate in Higher Education. Educause Quarterly(4), 28-33.

Kimble, C., Hildreth, P. M., \& Bourdon, I. (2008). Communities of Practice: Creating Learning Environments for Educators (Vol. 1). Charlotte, NC, USA: Information Age Publishing.

Kok, A. (2007). Intellectual Capital Management as Part of Knowledge Management Initiatives at Institutions of Higher Learning. The Electronic Journal of Knowledge Management, 5(2), 181-192.

Lam, W. (2005). Successful knowledge management requires a knowledge culture: a case study. Knowledge management research \& practice, 3(4), 206-217.

Lave, J. \& Wenger, E. (1991). Situated Learning: Legitimate Peripheral Participation, London: Cambridge University Press.

Lee, J. J. (2007). The shaping of the departmental culture: Measuring the relative influences of the institution and discipline. Journal of Higher Education Policy and Management, 29(1), 41-55.

Lee, L., Reinicke, B., Sarkar, R., \& Anderson, R. (2015). Learning Through Interactions: Improving Project Management Through Communities of Practice. Project Management Journal, 46(1), 40-52.

Leftheriotis, I., \& Giannakos, M. N. (2014). Using social media for work: Losing your time or improving your work? Computers in Human Behavior, 31(1), 134-142.

Leidner, D., \& Jarvenpaa, S. L. (1995). The use of information technology to enhance management school education: A theoretical view. Mis Quarterly, 19(3), 265-291.

Leidner, D., Koch, H., \& Gonzalez, E. (2010). Assimilating Generation Y IT New Hires into USAA's Workforce: The Role of an Enterprise 2.0 System. MIS Quarterly Executive, 9(4). 
Leonardi, P. M., Huysman, M., \& Steinfield, C. (2013). Enterprise social media: Definition, history, and prospects for the study of social technologies in organizations. Journal of Computer-Mediated Communication, 19(1), 1-19.

Leonardi, P. M., \& Meyer, S. R. (2015). Social media as social lubricant: How ambient awareness eases knowledge transfer. American Behavioral Scientist, 59(1), 10-34.

Lesser, E. L., \& Storck, J. (2001). Communities of practice and organizational performance. IBM systems journal, 40(4), 831-841.

Levy, M. (2009). Web 2.0 implications on knowledge management. Journal of knowledge management, 13(1), 120-134.

Lewis, B., \& Rush, D. (2013). Experience of developing Twitter-based communities of practice in higher education. Research in Learning Technology, 21(1), 1-13.

Liebowitz, J. (2001). Knowledge management and its link to artificial intelligence. Expert systems with applications, 20(1), 1-6.

Lin, T. (2012, 16 January). Cracking open the scientific process. New York Times, pp. 1-5.

Lok, P., \& Crawford, J. (2004). The effect of organisational culture and leadership style on job satisfaction and organisational commitment: A cross-national comparison. Journal of Management Development, 23(4), 321-338.

López-Nicolás, C., \& Meroño-Cerdán, Á. L. (2011). Strategic knowledge management, innovation and performance. International Journal of Information Management, 31(6), $502-$ 509.

Mäntymäki, M., \& Riemer, K. (2016). Enterprise social networking: A knowledge management perspective. International Journal of Information Management, 36(6), 1042-1052.

Marshall, M. N. (1996). Sampling for qualitative research. Family practice, 13(6), 522-526.

McCarthy, A. (2014). Leading During Uncertainty and Economic Turbulence: An Investigation of Leadership Strengths and Development Needs in the Senior Irish Public Sector. Advances in Developing Human Resources, 16(1), 54-73.

McLure, M., \& Faraj, S. (2000). "It is what one does": why people participate and help others in electronic communities of practice. The Journal of Strategic Information Systems, 9(2), 155-173.

McLure Wasko, M., \& Faraj, S. (2005). Why should I share? Examining social capital and knowledge contribution in electronic networks of practice. Mis Quarterly, 35-57.

Ng, L. L., \& Pemberton, J. (2013). Research-based communities of practice in UK higher education. Studies in Higher Education, 38(10), 1522-1539.

Ogbonna, E., \& Harris, L. C. (1998). Managing organizational culture: compliance or genuine change? British Journal of Management, 9(4), 273-288.

Ogbonna, E., \& Wilkinson, B. (2003). The false promise of organizational culture change: A case study of middle managers in grocery retailing. Journal of Management Studies, 40(5), 1151-1178.

Ortbach, K., \& Recker, J. C. (2014). Do good things and talk about them: a theory of academics usage of enterprise social networks for impression management tactics. Paper presented at the 
Proceedings of the 35th International Conference on Information Systems, Auckland, New Zealand.

Pascale, R. T. (1985). The paradox of" corporate culture": Reconciling ourselves to socialization. California management review, 27(2), 26-41.

Pascale, R. T., \& Sternin, J. (2005). Your company's secret change agents. Harvard business review, 83(5), 72-81.

Pinto, M. (2012). A Framework for Knowledge Managemt Systems Implementation in Higher Education. Paper presented at the Proceedings in ARSA-Advanced Research in Scientific Areas, Virtual.

Rai, R. K. (2011). Knowledge management and organizational culture: a theoretical integrative framework. Journal of knowledge management, 15(5), 779-801.

Ramachandran, S. D., Chong, S. C., \& Ismail, H. (2009). The practice of knowledge management processes: A comparative study of public and private higher education institutions in Malaysia. The Journal of Information and Knowledge Management Systems, 39(3), 203-222.

Ramakrishnan, K., \& Yasin, N. M. (2012). Knowledge Management System and Higher Education Institutions. International Proceedings of Computer Science and Information Technology, 37(1), 67-71.

Rao, M. (2010). KM and PM: Case Studies and Learnings from the Infotech Sector. In T. Kanti, M. E. Srikantaiah, D. Koenig, \& S. Hawamdeh (Eds.), Convergence of Project Management and Knowledge Management (pp. 308-317). Lanham, MD, USA: Scarecrow Press, Inc.

Razmerita, L., Kirchner, K., \& Nabeth, T. (2014). Social media in organizations: Leveraging personal and collective knowledge processes. Journal of Organizational Computing and Electronic Commerce, 24(1), 74-93.

Richter, A., \& Riemer, K. (2013). The Contextual Nature of Enterprise Social Networking: A Multi Case Study Comparison. Paper presented at the ECIS Completed Research, Utrecht, Netherlands.

Riemer, K., Finke, J., \& Hovorka, D. (2015). Bridging or Bonding: Do Individuals gain Social Capital from Participation in Enterprise Social Networks? Paper presented at the Thirty Sixth International Conference on Information Systems, Fort Worth, Texas, USA.

Rogers, E. M. (1995). Diffusion of Innovations (Fourth ed.). New York: The Free Press.

Rowley, J. (2000). Is higher education ready for knowledge management? International Journal of Educational Management, 14(7), 325-333.

Sathe, V. (1983). Implications of corporate culture: A manager's guide to action. Organizational dynamics, 12(2), 5-23.

Scanlan, J. M., Care, W. D., \& Udod, S. (2002). Unravelling the unknowns of reflection in classroom teaching. Journal of advanced nursing, 38(2), 136-143.

Schein, E. H. (2010). Organizational Culture and Leadership (Vol. 2). San Francisco: Jossey-Bass.

Schneckenberg, D. (2009). Web 2.0 and the empowerment of the knowledge worker. Journal of knowledge management, 13(6), 509-520. doi:doi:10.1108/13673270910997150 
Spendlove, M. (2007). Competencies for effective leadership in higher education. International Journal of Educational Management, 21(5), 407-417.

Stewart, T. A. (1997). Intellectual Capital: The New Wealth of Organizations. New York: Doubleday.

Suppiah, V., \& Singh Sandhu, M. (2011). Organisational culture's influence on tacit knowledgesharing behaviour. Journal of knowledge management, 15(3), 462-477.

Susman, G. I., \& Evered, R. D. (1978). An assessment of the scientific merits of action research. Administrative science quarterly, 23(4), 582-603.

Swart, J., \& Kinnie, N. (2003). Sharing knowledge in knowledge-intensive firms. Human resource management journal, 13(2), 60-75.

Szekeres, J. (2004). The invisible workers. Journal of Higher Education Policy and Management, 26(1), 7-22.

Taylor, J. (2006). "Big is beautiful." Organisational change in universities in the United Kingdom: New models of institutional management and the changing role of academic staff. Higher Education in Europe, 31(3), 251-273.

Tierney, W. G. (1988). Organizational culture in higher education: Defining the essentials. The Journal of Higher Education, 59(1), 2-21.

Tippins, M. J. (2003). Implementing knowledge management in academia: teaching the teachers. International Journal of Educational Management, 17(7), 339-345.

Trice, H. M., \& Beyer, J. M. (1993). The Cultures of Work Organizations. Englewood Cliffs, NJ, USA: Prentice-Hall, Inc.

Von Krogh, G. (2012). How does social software change knowledge management? Toward a strategic research agenda. The Journal of Strategic Information Systems, 21(2), 154-164.

Wang, S., \& Noe, R. A. (2010). Knowledge sharing: A review and directions for future research. Human Resource Management Review, 20(2), 115-131.

Wang, Z., \& Wang, N. (2012). Knowledge sharing, innovation and firm performance. Expert systems with applications, 39(10), 8899-8908.

Wenger, E. (1999). Communities of Practice: Learning, Meaning, and Identity. Cambridge: Cambridge University Press.

Wenger, E., \& Snyder, W. M. (2000). Communities of practice: The organizational frontier. Harvard business review, 78(1), 139-146.

Wi, C. (2015). The Engaged Leader: A Strategy for Your Digital Transformation. PA, USA: Wharton Digital Press.

Wiig, K. M. (1999). What future knowledge management users may expect. Journal of knowledge management, 3(2), 155-166.

Willmott, H. (1993). Strength is ignorance; slavery is freedom: managing culture in modern organizations. Journal of Management Studies, 30(4), 515-552. 
Wohlmuther, S. (2008). 'Sleeping with the enemy': how far are you prepared to go to make a difference? A look at the divide between academic and allied staff. Journal of Higher Education Policy and Management, 30(4), 325-337.

Yates, D., \& Paquette, S. (2011). Emergency knowledge management and social media technologies: A case study of the 2010 Haitian earthquake. International Journal of Information Management, 31(1), 6-13.

Zboralski, K. (2009). Antecedents of knowledge sharing in communities of practice. Journal of knowledge management, 13(3), 90-101.

Zhao, F., \& Kemp, L. (2013). Exploring individual, social and organisational effects on Web 2.0-based workplace learning: a research agenda for a systematic approach. Research in Learning Technology, 21(1), 1-15.

Copyright: (C) 2018 Duane \& Corcoran. This is an open-access article distributed under the terms of the Creative Commons Attribution-NonCommercial 3.0 Australia License, which permits non-commercial use, distribution, and reproduction in any medium, provided the original author and AJIS are credited.

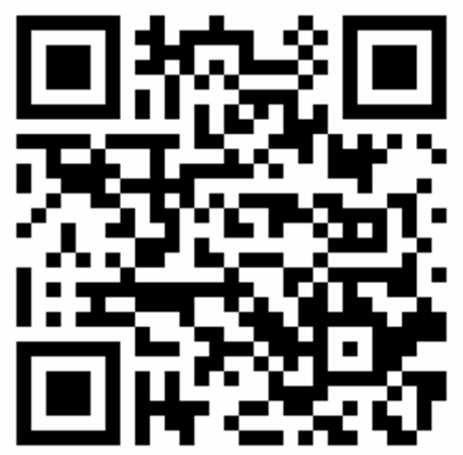

